\title{
Effects of extraction solvent and time on the oil yield, total phenolic content, carotenoid and antioxidant activity of Australian chia seed (Salvia hispanica L.) oil
}

\author{
${ }^{1,2}$ Ishak, I., ${ }^{1, *}$ Ghani, M.A. and ${ }^{1}$ Yuen, J.Z. \\ ${ }^{1}$ Department of Food Sciences, Faculty of Science and Technology, Universiti Kebangsaan Malaysia, 43600 \\ Bangi, Selangor, Malaysia \\ ${ }^{2}$ Halal Products Research Institute, Universiti Putra Malaysia, Putra Infoport, 43400 UPM Serdang, \\ Selangor, Malaysia
}

Article history:

Received: 22 May 2020

Received in revised form: 27

July 2020

Accepted: 5 November 2020

Available Online: 6

December 2020

\section{Keywords:}

Chia seed oil,

Antioxidant activity,

Total phenolic content,

Total carotenoid content,

Acetone,

Hexane

DOI:

https://doi.org/10.26656/fr.2017.4(S4).006

\begin{abstract}
The oil yield, total phenolic content (TPC), total carotenoid content (TCC) and antioxidant activity of Australian chia seed (Salvia hispanica L.) oil under solvents polarity and extraction times were studied. The chia seed oils were obtained by using organic solvents in the Soxhlet method with different extraction times including acetone 4 hrs (A4), acetone $8 \mathrm{hrs}(\mathrm{A} 8)$ and hexane $8 \mathrm{hrs}(\mathrm{H} 8)$ as a control. The oil yield for the control sample (36.1\%) showed significant $(\mathrm{p} \leq 0.05)$ higher than A4 $(33.53 \%)$ and A8 $(33.73 \%)$. TPC for chia seed oil (A4) was significantly higher $(\mathrm{p} \leq 0.05)$ than A8 and H8. Meanwhile, chia seed oil (A8) contained the highest TCC over A4 and H8. The antioxidant activity of chia seed oil was determined by DPPH (2-diphenyl-1-picrylhydrazyl) scavenging activity, FRAP (Ferric reducing antioxidant power assay), BCBA (Beta-carotene bleaching assay) and TBA (Lipid Peroxidation Inhibition Assay), respectively. Chia seed oil obtained by acetone extraction for $4 \mathrm{hrs}$ revealed higher antioxidant capacities (DPPH, BCBA and TBA) compared to chia seed oils from A8 and H8. However, chia seed oil (H8) showed the lowest total (phenolic and carotenoid contents) and antioxidant capacities. The correlation between the antioxidant content and the antioxidant activities were conducted to determine their relationship. TPC and TCC were strongly correlated with BCBA ( $\mathrm{r}=$ 0.999) and TBA $(r=0.997)$. The results found Australian chia seed oil extracted by acetone for 4 hrs (A4) had higher contents of phenolic and antioxidant activity than control (H8) due to high polarity of acetone to the antioxidant compounds. In conclusion, acetone can be applied as an alternative extraction solvent to increase the total phenolic and carotenoid contents as well as antioxidant activity of Australian chia seed oil.
\end{abstract}

\section{Introduction}

Chia seeds are cultivated widely in Mexico, Bolivia, Argentina and Guatemala (Rosas-Mendoza et al., 2017). Chia seed comprise about $25-35 \%$ oil, $22 \%$ fibre, and $24 \%$ protein. Chia seed also contain other important nutritional components such as vitamins, minerals and natural antioxidants (Borneo et al., 2010). Chia seeds have great potential in the health, nutrition, animal food, pharmaceutical and nutraceutical (Muñoz et al., 2013).

Chia seed oil constitutes the highest content of polyunsaturated fatty acids (PUFAs) (62\% linolenic acid and $19 \%$ linoleic acid) among all of the vegetable oils (Silva et al., 2016). These fatty acids are important for healthy growth and body developmental. Also, PUFAs play an important role in the prevention and treatment of coronary artery disease, hypertension, diabetes, arthritis, inflammatory disorders and cancer (Artemis and Simopoulos, 2002). Although chia seed oil is good for human health, they are easy to oxidize due to high in unsaturated double bonds which can affect the food quality and shorten the shelf life of the food (Ixtaina et al., 2012).

Antioxidants are compounds that can delay the process of oxidation by reacting with free radicals, acting as oxygen receptors and iron-binding agents (Sang et al., 2002). Phenolic compounds, tocopherols and carotenoids were identified as antioxidants in chia seed oil (Shen et al., 2018). The phenolic compounds found in chia seed oil are rosmarinic acid (Cvetkovikj et al., 2013), 
chlorogenic acid, caffeic acid and flavonol (myricetin, quercetin and kaempferol) (Marineli et al., 2014). Ixtaina et al. (2011) reported that chia seed oil also consists in the high concentration of tocopherol $(238-427 \mathrm{mg} / \mathrm{kg})$, mostly $\gamma$-tocopherol $(>85 \%)$, while, $\delta$-tocopherol and $\alpha$ tocopherol were found in small amounts. Ixtaina et al. (2011) indicated that the total carotenoid content of chia seed oil ranged from $0.53 \mathrm{mg} / \mathrm{kg}$ to $1.21 \mathrm{mg} / \mathrm{kg}$, which most of the measured amount represents to $\beta$-carotene. So far, there have been no studies carried out on the antioxidant activities of chia seed oil from different extraction solvents (acetone and hexane).

Extraction time is also an important parameter that influences the extraction yield of antioxidant compounds. Increased extraction time can lead to higher oil yields by increasing solvent exposure to the samples (Pichai and Krit, 2015). However, after an extraction efficiency reaches a maximum of a specific time, continuous extraction can cause degradation or decomposition of bioactive compounds, especially antioxidants (Kim, 2017). Generally, labile compounds such as antioxidants lose their effectiveness at high temperatures and prolonged-time during extraction (Routray and Orsat, 2012). Increased extraction times are wasteful based on the industrial viewpoint and potentially increase in solvent loss through evaporation which directly affects the solvent-solubility extraction process (Tan et al., 2013). The purpose of this study was to identify the suitable solvent and time extraction, which increase the yield and antioxidant capacity of chia seed oil.

\section{Materials and methods}

\subsection{Materials}

Black chia seeds (Salvia hispanica L.) from Australia were used in the study and stored in the refrigerator. The total moisture content was $5.3 \%$. Before oil extraction, the seeds were milled by using a coffee grinder (HanJiaOurs, China) for $15 \mathrm{~s}$ into finely powdered. Acetone ( $\mathrm{R} \& \mathrm{M}$ Chemicals) and hexane $(\mathrm{QReC})$ were used for extracting oil from chia seeds. All chemicals used in the antioxidant activities were analytical grades. Meanwhile, $\alpha$-tocopherol (SigmaAldrich Chemical Co.) was used as the standard for comparison with chia seed oil in the antioxidant activity methods.

\subsection{Extraction of chia seed oil}

The Soxhlet procedure described by AOAC (1990) was used for the extraction and determination of the percentage of oil yield from the chia seed. Milled chia seeds were weighed and placed in the thimble, and approximately $250 \mathrm{~mL}$ of extraction solvent (hexane or acetone) was poured into a weighed round-bottom flask. The solvent was heated to boil based on their boiling points (acetone: $56^{\circ} \mathrm{C}$ and hexane: $63-69^{\circ} \mathrm{C}$ ). The chia seed oil was extracted using acetone in $4 \mathrm{hrs}$ and $8 \mathrm{hrs}$, identified as A4 and A8. Meanwhile, the extraction also carried out using hexane identified as $\mathrm{H} 8$ and used as control. Most of the chia seed oil extraction conducted using hexane as a standard solvent based on the previous studies (Álvarez-Chávez et al., 2008; Ixtaina et al., 2010; Ixtaina et al., 2011; Dąbrowski et al., 2016; Scapin et al., 2017 ) at different extraction times ( $8 \mathrm{hrs}$ to $18 \mathrm{hrs}$ ). Extraction time for $8 \mathrm{hrs}$ was used in the study to reduce the energy and electrical consumption of the Soxhlet apparatus. The solvent removal was carried out under vacuum in a rotary evaporator (Büchi, Flawil, Switzerland) for 30 mins and used at $40^{\circ} \mathrm{C}$. Finally, extracted chia seed oil was weighed to determine the oil yield and transferred into a dark bottle, flushed with nitrogen gas and stored at $4^{\circ} \mathrm{C}$ until analyzed for antioxidant activities. All determinations were performed in triplicate. Three chia seed oil samples were obtained.

\subsection{Determination of oil yield}

The percentage of oil yield was calculated by measuring the weight of the extracted oil and the weight of the chia powder used for oil extraction as described by Khajeh (2011).

$$
\text { Oil Yield (\%) }=\frac{\text { Weight of extracted oil }}{\text { Weight of seed }} \times 100
$$

\subsection{Determination of total phenolic contents}

Total phenolic content of the chia seed oils was measured by the Folin-Ciocalteu procedure with few modifications (Singleton et al., 1999). Chia seed oil diluted with acetone or hexane and mixed with the FolinCiocalteu reagent. Next, $7.5 \%$ sodium carbonate $\left(\mathrm{Na}_{2} \mathrm{CO}_{3}\right)$ solution was added after $6 \mathrm{~min}$, and the tubes were standing in the dark at room temperature for $2 \mathrm{hrs}$. Then, the absorbance was determined at $765 \mathrm{~nm}$ using a spectrophotometer (Shimadzu UV-1800, Japan) and compared with a calibration curve of gallic acid developed: $Y=0.0078 x+0.0514, R^{2}=0.9994$ (ranged from 0 to $100 \mathrm{ppm})$. The results were shown as milligram (mg) of gallic acid equivalent per gram of oil extract (mg/g GAE of oil).

\subsection{Determination of total carotenoids}

Total carotenoid contents were determined by the method of Mínguez-Mosquera et al. (1991). About $0.2 \mathrm{~g}$ of chia seed oil was fully dissolved in $2 \mathrm{~mL}$ of cyclohexane. The absorbance of the solution was measured at $470 \mathrm{~nm}$ wavelengths for carotenoids by 
using UV spectrophotometer (Shimadzu UV-1800, Japan). The carotenoid contents were quantified as follows:

Total carotenoid content $(\mathrm{mg} / \mathrm{kg}$ of oil $)=\frac{\mathrm{A}_{470^{-10^{6}}}}{2000 \times 100 \times \mathrm{d}}$

Where $A$ is the sample of the absorption value, 470 is the extinction coefficient for carotenoids, 2000 is the extinction coefficient for carotenoids (lutein being a major component in the carotenoid fraction), and $d$ is the spectrophotometer cell thickness $(1 \mathrm{~cm})$.

\subsection{Antioxidant activity}

2.6.1 Determination of free radical scavenging (DPPH) assay

The DPPH activity of chia seed oil was measured (Ruttarattanamongkol and Petrasch, 2016) with few modifications. About $0.2 \mathrm{~mL}$ of chia seed oil was mixed with $10 \mathrm{~mL}$ of methanol for $1 \mathrm{~min}$ by using vortex shaker. The sample mixture was centrifuged at $4000 \mathrm{rpm}$ for $5 \mathrm{~min}$. Next, $0.6 \mathrm{~mL}$ of supernatant was mixed with 2 $\mathrm{mL}$ of $0.1 \mathrm{mmol} / \mathrm{L}$ DPPH solution in methanol. The mixture was stored for 60 mins in the dark place. The absorbance of the sample mixture was read at $517 \mathrm{~nm}$ using UV spectrophotometer (Shimadzu UV-1800, Japan). The antioxidant activity of chia seed oil was expressed as percentage inhibition of DPPH radical as follows:

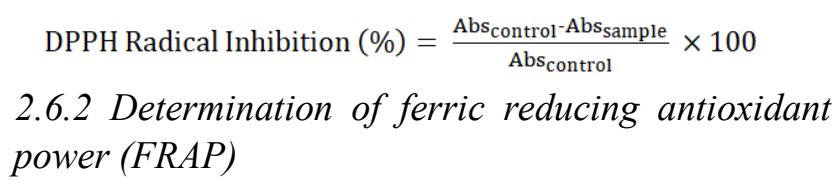

FRAP of the chia seed oil was determined (Benzie and Strain, 1996). The FRAP reagent (Fe (III) solution and TPTZ) was prepared by the mixture of $0.3 \mathrm{M}$ acetate buffer $(25 \mathrm{~mL})$, solution of $10 \mathrm{mM}$ TPTZ $(2,4,6$-tri(2pyridyl)-s-triazine) $(2.5 \mathrm{~mL})$ and solution of $20 \mathrm{mM}$ ferric chloride $(2.5 \mathrm{~mL})$. About $200 \mu \mathrm{L}$ of diluted chia seed oil (10 mg of chia seed oil/100 mL of solvent) was added into the test tube containing $1.8 \mathrm{~mL}$ of FRAP reagent and incubated in the water bath for $30 \mathrm{~min}$ at $37^{\circ}$ C. Then, the absorbance of the coloured sample solution was measured at $593 \mathrm{~nm}$ using a spectrophotometer (Shimadzu UV-1800, Japan). The Trolox solution (ranged from 0 to $100 \mathrm{ppm}$ ) was employed as a standard for the calibration curve: $\mathrm{Y}=0.095 \mathrm{x}+0.0882, \mathrm{R}^{2}=$ 0.9922 , and the results were stated in micromole the Trolox equivalents per gram of oil $(\mu \mathrm{mol}$ Trolox/g of oil).

\subsection{3 $\beta$-Carotene bleaching assay (BCBA)}

The $\beta$-carotene bleaching activity of the chia seed oil was measured (Shon et al., 2003) with some modifications. The solution of $\beta$-carotene was made by mixing $3 \mathrm{mg}$ of $\beta$-carotene in $10 \mathrm{~mL}$ of chloroform.
Next, $4 \mathrm{~mL}$ of $\beta$-carotene solution, $80 \mathrm{mg}$ of linoleic acid and $800 \mathrm{mg}$ of Tween 80 were added into the $500 \mathrm{~mL}$ round-bottom flask. Distilled water $(200 \mathrm{~mL})$ was added to the round-bottom flask with vigorous shaking, after removing chloroform by purified nitrogen gas. The emulsion formed $(3 \mathrm{~mL})$ and $0.2 \mathrm{~mL}$ of chia seed oil sample $(400 \mu \mathrm{g}$ of chia seed oil $/ \mathrm{mL}$ of hexane or acetone) were mixed in glass tubes and heated in a water bath at $50^{\circ} \mathrm{C}$. Then, the absorbance of the $\beta$-carotene mixtures was measured at $470 \mathrm{~nm}$ using a spectrophotometer (Shimadzu UV-1800, Japan) at 30 min intervals for $2 \mathrm{hrs}$. $\alpha$-tocopherol was used as a standard antioxidant. The inhibition rate was calculated as follows:

$$
\text { Inhibition of } \beta \text {-Carotene bleaching }(\%)=\frac{A_{S}-A_{i}}{A_{S}} \times 100
$$

Where $A_{s}=$ Initial absorbance of the sample and $A_{i}=$ Absorbance of the sample after $2 \mathrm{hrs}$

\subsubsection{Thiobarbituric acid (TBA) assay}

The TBA content of the chia seed oil was determined by using the method of Kikuzaki and Nakatani (1993). About $1 \mathrm{~mL}$ of the sample solution was mixed with $2 \mathrm{~mL}$ of trichloroacetic acid (20\%) and $2 \mathrm{~mL}$ of TBA $(0.67 \%)$. The sample solution was prepared by dissolving chia seed oil $(200 \mu \mathrm{L})$ in $2 \mathrm{~mL}$ of $65 \%$ ethanol. Next, the solution was mixed with $2 \mathrm{~mL}$ of linoleic acid $(2.5 \%)$ in absolute ethanol, $4 \mathrm{~mL}$ of $0.05 \mathrm{M}$ phosphate buffer and 2 $\mathrm{mL}$ of distilled water, and stored in the dark at $40^{\circ} \mathrm{C}$. Next, the mixture was incubated in a boiling water bath for 10 mins. After cooling, the mixture was centrifuged at $3000 \mathrm{rpm}$ for $20 \mathrm{mins}$. The absorbance of the supernatant was measured at a wavelength of $532 \mathrm{~nm}$ (Shimadzu UV-1800, Japan). The inhibition rate was measured using the following equation:

$$
\text { Inhibition of TBA formation (\%) }=\frac{A_{c}-A_{s}}{A_{c}} \times 100
$$

Where $\mathrm{A}_{\mathrm{c}}=$ Absorbance of the control and $\mathrm{A}_{\mathrm{s}}=$ Absorbance of the sample

\subsection{Statistical analysis}

All experimental data were conducted in triplicate and expressed as mean \pm standard deviation. The statistical analyses were performed using MINITAB software version 9.1. Data were subjected to analysis of variance (ANOVA) at 95\% confidence level $(p \leq 0.05)$ to find any significant difference between samples. A Pearson correlative coefficient was computed to determine the correlation between antioxidant results obtained for all samples tested.

\section{Results and discussion}

\subsection{Extraction yield of chia seed oil}

The oil yield of chia seeds extracted by different 
solvents and time are presented in Table 1. It can be observed that the total lipids of chia seed obtained from various treatments showed a significant difference $(\mathrm{p} \leq$ 0.05 ) each other. The yield of chia seed oils ranged from $33.53-36.1 \%$, which was similar to the results reported by Noshe and Al-bayyar (2017) and Dąbrowski et al. (2018a). The content of oil in chia seeds obtained in the present study in the range of values $30-35 \%$ as discussed in the EFSA report (EFSA, 2009). Ayerza et al. (2009) reported that the location of the chia seed cultivation strongly influenced the oil content, which can be varied from 26.0-33.5\%. The results showed that the Soxhlet extraction method using hexane for $8 \mathrm{hrs}$ is the most effective to obtain the highest yield of chia seed oil. Moradi et al. (2018) described hexane as an excellent non-polar solvent in terms of oil extraction yield when compared to polar organic solvents such as acetone, methanol and ethanol, respectively which showed low efficiency. Thus, the non-polar of hexane are responsible for higher diffusion and chia seed oil yield in the extraction.

Table 1. The oil yield (\%) of Australian chia seeds extracted by different solvents and times

\begin{tabular}{cc}
\hline Chia seed oil & Yield of chia seed oil (\%) \\
\hline A4 & $33.53 \pm 0.61^{\mathrm{b}}$ \\
A8 & $33.73 \pm 0.93^{\mathrm{b}}$ \\
H8 & $36.10 \pm 0.80^{\mathrm{a}}$ \\
\hline
\end{tabular}

Values in each column with different letters are significantly different $(\mathrm{p} \leq 0.05)$. A4: Chia seed oil extracted by acetone for $4 \mathrm{hrs}$, A8: Chia seed oil extracted by acetone for $8 \mathrm{hrs,} \mathrm{H8:}$ Chia seed oil extracted by hexane for $8 \mathrm{hrs}$.

\subsection{Total phenolic contents (TPC) of chia seed oil}

TPC of the chia seed oils from different solvents and times are shown in Table 2. Chia seed oil extracted by acetone for $4 \mathrm{hrs}$ showed the highest phenolic content indicated that a significant amount of phenolics were obtained from polar solvent at a shorter time. On the other hand, chia seed oil obtained by hexane showed a significantly different $(p \leq 0.05)$ than the others. This might due to the lower value of phenolic contents from the polar differences between hexane and acetone towards antioxidant compounds. Antioxidant activity is strongly associated with TPC in the plant (OliveiraAlves et al., 2017). Sri Widyawati et al. (2014) confirmed that the polarity differences of extraction solvents affect the composition and antioxidant activity of the bioactive compounds in the plant sources. The recovery of polyphenols from the plant is also influenced by their solubility in the solvent used for the extraction process (Naczk and Shahidi, 2006). The measured amount of phenolic content obtained can be related to the presence of polyphenolic compounds such as chlorogenic acid, kaempferol, quercetin, myricetin, and caffeic acid in the chia seed oils obtained by different extraction methods (Ixtaina et al., 2011; Marineli et al., 2014). Phenolic compounds such as chlorogenic acid, caffeic acid, myricetin, quercetin and kaempferol are hydrophilic and easily extracted by polar solvent like acetone (Edwards et al., 2015). Thus, acetone could extract more phenolic compounds in chia seed oil compared to hexane. Acetone is commonly used as an organic solvent in the extraction of phenolic compounds from plants (Haminiuk et al., 2014; Naczk and Shahidi, 2006). On the other hand, hexane extracts more nonpolar compounds such as lignin, waxes, lipids, aglycones, tocopherols, sterols, and terpenoids. TPC for chia seed oil (A8) was significantly lower $(p \leq 0.05)$ than that of acetone extraction at $4 \mathrm{hrs}$. Therefore, extraction time plays a vital role in maximizing the recovery of polyphenols in chia seed oil. Although longer extraction time may increase extraction yields of chia seed oil (Table 1), phenolic compounds were over-exposed to temperature, light and oxygen which lead to oxidation as well as enzyme degradation (Go et al., 2014; Saphier et al., 2017).

Table 2. Total phenolic and carotenoid content of chia seed oils extracted by different solvents and times

\begin{tabular}{ccc}
\hline Chia seed oil & TPC (mg GAE/g of oil) & TCC (mg/kg of oil) \\
\hline A4 & $75.13 \pm 2.22^{\mathrm{a}}$ & $2.93 \pm 0.18^{\mathrm{b}}$ \\
A8 & $61.88 \pm 1.96^{\mathrm{b}}$ & $3.51 \pm 0.16^{\mathrm{a}}$ \\
H8 & $14.44 \pm 2.67^{\mathrm{c}}$ & $1.10 \pm 0.06^{\mathrm{c}}$ \\
\hline
\end{tabular}

Values in each column with different letters are significantly different $(\mathrm{p} \leq 0.05)$. A4: Chia seed oil extracted by acetone for 4 hrs, A8: Chia seed oil extracted by acetone for 8 hrs, H8: Chia seed oil extracted by hexane for $8 \mathrm{hrs}$.

\subsection{Total carotenoid content (TCC) of chia seed oil}

The values found for TCC of chia seed oils extracted by different solvents and times are shown in Table 2 . Chia seed oil (A8) contained significantly higher TCC (p $\leq 0.05$ ) compared to others. Meanwhile, chia seed oil (H8) had the lowest content of total carotenoids. The result obtained in accordance with the previous study by Ixtaina et al. (2011) reported that the solvent extraction method using hexane varied between 0.53 to $1.21 \mathrm{mg} / \mathrm{kg}$. Meanwhile, Dąbrowski et al. (2016) stated that TCC of chia seed oil extracted by acetone was $8.40 \mathrm{mg} / \mathrm{kg}$. According to Dąbrowski et al. (2018a), $\beta$-carotene is the main compound in chia seed oil samples from various sources and origins. Besides, other carotenoids such as lutein and 9-cis-3-carotene were also present (Dąbrowski et al., 2018a). However, chia seed oil extracted by supercritical carbon dioxide enriched with acetone showed that most of the carotenoid compounds are lutein followed by $\beta$-carotene and minor concentration of 9-cis- 
$\beta$-carotene (Dąbrowski et al., 2018b). Significant impacts can be observed $(\mathrm{p} \leq 0.05)$ in the TTC of chia seed oil when applying acetone at different extraction times. The results showed an increase in TCC of chia seed oil from $4 \mathrm{hrs}$ to $8 \mathrm{hrs}$ of the acetone extraction. According to Norshazila et al. (2017), there is an increase in pumpkin carotenoid contents at higher extraction time from $8 \mathrm{hrs}$ to 16 hours using food grade solvents. It is found that acetone used in the extraction method was efficient in obtaining carotenoid content of chia seed oil at a longer time. According to Dąbrowski et al. (2016), acetone is the most effective solvent for carotenoid extraction in chia seed oil. Therefore, the high polarity of acetone in the extraction method of chia seed oil allows for obtaining more amphiphilic compounds, including carotenoids.

\subsection{Determination of antioxidant activity}

The results obtained for the determination of antioxidant capacities of chia seed oils based on the different solvents and times as compared with antioxidant standard ( $\alpha$-tocopherol) are shown in Table 3.

\subsubsection{Free radical scavenging assay (DPPH) of chia seed oil}

Table 3 shows the antioxidant activity of chia seed oils produced by different solvents and extraction times in DPPH method. Inhibition percentage of DPPH radical activity in the chia seed oils showed a significant difference ( $p \leq 0.05$ ) compared to the antioxidant standard. $\alpha$-tocopherol displayed the highest antioxidant activity, followed by A4, A8 and H8. Chia seed (Salvia hispanica) oil used in the present study showed higher antioxidant activity than other oil from Salvia species except for Salvia candidissima subsp. Candidissima (49.7\%). The values obtained were as follows: S. caespitosa (41.3\%), S. hypargeia (34.6\%), S. euphratica subsp. Euphratica (20.7\%), and $S$. sclarea (23.4\%), respectively (Tepe et al., 2006). Sargi et al. (2013) reported that the activity of free radical scavenging for chia seed oil was higher than that of hemp seeds but lower than flax seeds. Antioxidants in chia seed oil have a high ability to trap DPPH free radicals. However, the inhibition percentage of free radical scavenging activity for the chia seed oil in this study was lower than Martínez-Cruz and Paredes-López (2014). It observed that high correlation between phenolics $(r=0.996)$ and carotenoids $(r=0.863)$ to reduce free radical DPPH by chia seed oil, as shown in Table 4. A positive correlation demonstrates that phenolic compounds and carotenoids are mostly responsible for free radical scavenging activity of chia seed oil.

\subsubsection{Ferric reducing antioxidant power (FRAP) of chia seed oil}

Table 3 shows the FRAP (antioxidant power of iron reduction) values of chia seed oils extracted by different solvents and times. FRAP values of chia seed oils (A4, A8 and H8) and $\alpha$-tocopherol showed significant difference $(\mathrm{p} \leq 0.05)$ between them. Reduction power of chia seed oils by using acetone at different times (A4 and A8) showed no significant difference $(p \geq 0.05)$. The values for both extractions are considerably higher $(\mathrm{p} \leq$ 0.05) compared to hexane extraction (H8). The results also showed chia seed oil (A8) produced the highest FRAP value compared to other oil samples. This might be due to the largest amount of carotenoid content found in chia seed oil (A8). Positive correlation between FRAP method with the total carotenoid and phenolic content were $(r=0.998)$ and $(r=0.930)$, respectively. It shows that the antioxidant activity of chia seed oil in the FRAP method strongly related to the carotenoid and phenolic compounds. Meneses et al. (2013) stated that extraction solvents have a significant impact on the recovery of phenolic compounds. According to Alothman et al. (2009), high antioxidant activities from FRAP results much depends on the high polarity of the solvent. This may suggest that the antioxidant capacity of chia seed oil extracted by acetone is higher and better than extracted oil by hexane in the FRAP determination.

\subsection{3 $\beta$-Carotene bleaching assay of chia seed oil}

Table 3 shows that the antioxidant capacities of chia seed oils (A4, A8 and H8) were $38.24 \%, 33.72 \%$ and $12.53 \%$, respectively, compared to $51.94 \%$ for $\alpha$ tocopherol as a standard antioxidant. No significant differences $(p \geq 0.05)$ in antioxidant capacity were found between the chia seed oils (A4 and A8). Thus, acetone

Table 3. Antioxidant activity of chia seed oils extracted by different solvents and times

\begin{tabular}{lcccc}
\hline Chia seed oil & $\begin{array}{c}\text { DPPH radical } \\
\text { scavenging }(\%)\end{array}$ & $\begin{array}{c}\text { FRAP } \\
(\mu \mathrm{mol} \text { Trolox/g of oil) }\end{array}$ & $\begin{array}{c}\text { Inhibition of } \beta \text { - } \\
\text { Carotene bleaching }(\%)\end{array}$ & $\begin{array}{c}\text { Inhibition of lipid } \\
\text { peroxidation activity }(\%)\end{array}$ \\
\hline Standard antioxidant $(\alpha$-tocopherol) & $78.33 \pm 1.18^{\mathrm{a}}$ & $2574.42 \pm 6.42^{\mathrm{a}}$ & $51.94 \pm 3.10^{\mathrm{a}}$ & $82.23 \pm 1.55^{\mathrm{a}}$ \\
A4 & $49.62 \pm 3.00^{\mathrm{b}}$ & $119.72 \pm 2.43^{\mathrm{b}}$ & $38.24 \pm 3.25^{\mathrm{b}}$ & $67.11 \pm 2.99^{\mathrm{b}}$ \\
A8 & $44.10 \pm 2.12^{\mathrm{c}}$ & $132.34 \pm 6.42^{\mathrm{b}}$ & $33.72 \pm 1.78^{\mathrm{b}}$ & $55.26 \pm 2.31^{\mathrm{c}}$ \\
H8 & $31.28 \pm 1.60^{\mathrm{d}}$ & $32.80 \pm 4.21^{\mathrm{c}}$ & $12.53 \pm 1.75^{\mathrm{c}}$ & $31.39 \pm 2.32^{\mathrm{d}}$ \\
\hline
\end{tabular}

Values in each column with different letters are significantly different $(\mathrm{p} \leq 0.05)$. A4: Chia seed oil extracted by acetone for 4 hrs, A8: Chia seed oil extracted by acetone for $8 \mathrm{hrs,} \mathrm{H8:} \mathrm{Chia} \mathrm{seed} \mathrm{oil} \mathrm{extracted} \mathrm{by} \mathrm{hexane} \mathrm{for} 8$ hrs. 
extraction at different times did not influence on the antioxidant activity of chia seed oil in the $\beta$-Carotene bleaching method. However, chia seed oil (H8) presented the lowest antioxidant activity. $\beta$-Carotene bleaching method involved the reaction of free radicals formed by hydroperoxides from the oxidation of linoleic acid with $\beta$-carotene. The bleaching rate of $\beta$-carotene increased with a low amount of antioxidants in the oil samples during the oxidation reaction. The presence of antioxidants retarded the radicals produced from the linoleic acid oxidation, which is activated the bleaching of $\beta$-carotene (Yunfeng et al., 2018). The inhibition activity of $\beta$-carotene bleaching for chia seed oils was lower than previous research by Reyes-Caudillo et al. (2008) that the values of Mexican chia seed oil from two regions were $79.3 \%$ and $73.5 \%$, respectively. Furthermore, chia seed oils in this study also showed a lower antioxidant activity compare to oil from Salvia species such as $S$. caespitosa (55.9\%), $S$. candidissima (62.3\%), S. hypargeia (62.9\%), $S$. euphratica (59.1\%) and S. sclarea (63.5\%) (Tepe et al., 2006). Although the antioxidant activity of chia seed oil was lower than the other studies, a significantly strong correlation $(r=0.999)$ between $\beta$-carotene inhibition activity and the TPC of chia seed oils were obtained. Antioxidants can stabilize reactive oxygen species from linolenic acid oxidation (Reyes-Caudillo et al., 2008). Chlorogenic and caffeic acids are phenolic compounds that can act as secondary antioxidants that prevent oxidation by suppressing oxidizing agents, including metal ions, single oxygen, and pro-oxidative enzymes (Sahreen et al., 2011). Different extraction solvents applied in the extraction method significantly affect the inhibitory activity of $\beta$-carotene bleaching for chia seed oils. These results indicate that the solvent polarity influenced the antioxidant activity of chia seed oils. Several causes might be responsible for the results obtained. The H-atom transfer (HAT) mechanism has taken place between chia seed oil (contains phenolic antioxidant) by transferring hydrogen to the peroxyl radical in the linoleic acid oxidation (Valgimigli et al., 2009). Litwinienko and Ingold (2003) revealed that the solvent polarity affects the capacity of the hydrogen transferring. Hexane (high hydrophobicity) has the ability to delay the phenol-peroxyl radical reactions compared to acetone (smaller hydrophobicity) (Litwinienko and Ingold, 2004). It may describe the lowest value of antioxidant activity obtained in chia seed oil (H8) for $\beta$-Carotene bleaching method.

\subsubsection{Thiobarbituric acid assay (TBA) of chia seed oil}

Table 3 shows that $\alpha$-tocopherol has the highest level of antioxidant activity (82.23\%) compared to other chia seed oils (A4, A8 and H8) with TBA values of $67.11 \%$, $55.26 \%$ and $31.39 \%$, respectively. Chia seed oil (A4) showed higher TBA value $(p \leq 0.05)$ than other oil samples. This assay is used a lot in the determination of antioxidant capacities regarding lipid peroxidation (Moon and Shibamoto, 2009). Single oxygen is the catalyst for the formation of hydrogen peroxide and hydroxyl radicals in the lipid peroxidation system (Siddhuraju et al., 2002). Phenolic plays an essential role as a single oxygen trap and free radical scavenger by donating hydrogen from their phenolic groups (ReyesCaudillo et al., 2008). The formation of MDA can be inhibited by the existence of polyphenolic compounds (Zaki, 2018). Low phenolic content led to insufficient hydrogen donor to trap single oxygen from the linoleic acid peroxidation. The lowest TBA value of chia seed oil (H8) obtained in this study showed similar result to previous lipid oxidation method ( $\beta$-Carotene bleaching assay). It is demonstrated that hexane was not an effective solvent to retard the oxidation occurs in the TBA assay due to their hydrophobic characteristics. Therefore, it confirmed that higher TPC of chia seed oil (A4) compared to other oil samples proved the best antioxidant capacity to reduce the lipid peroxidation in both methods (TBA and BCBA).

\subsection{The correlation between antioxidant results obtained}

Based on the Table 4, there was a significant correlation $(\mathrm{p} \leq 0.05)$ between TPC with BCBA $(\mathrm{r}=$ $0.999)$ and TBA $(r=0.997)$. The positive correlation between TPC and BCBA is due to the polyphenols in chia seed oil acts as a hydrogen donor to the oxygen in the $\beta$-carotene peroxidation model system (Tepe et al., 2006). The positive correlation obtained by Dąbrowski et al. (2018b) who found that chia seed oil extracted by supercritical carbon dioxide enriched with $10 \%$ acetone contained the highest amount of carotenoids and polyphenols. Thus, polyphenols in the chia seed oils extracted by acetone retarded the lipid radicals formed during linolenic acid oxidation by delaying the discolouration of the $\beta$-carotene. Similar finding reported by Ferhat et al. (2017) who stated that high correlation was found between TPC and the BCBA ( $r=0.725, p \leq$ $0.01)$ of Algerian pomace olive oil. The inhibitory effects of polyphenols towards MDA formation during fat peroxidation also explain the positive relationship between TPC and TBA (Zaki, 2018). Meanwhile, carotenoids had a high correlation with FRAP ( $\mathrm{r}=$ 0.998). This correlation can be described by the presence of carotenoid compounds (zeaxanthin and lycopene) which contributed to the high ferric reduction activity (Maruyama et al., 2014; Müller et al., 2011). In addition, DPPH showed a good correlation $(\mathrm{p} \leq 0.05)$ with TBA ( $\mathrm{r}$ $=0.999$ ). 
Table 4. Simple linear correlations calculated for relationships between total phenolic content, carotenoid and antioxidant activity of chia seed oils extracted by different solvents and times

\begin{tabular}{lccccc}
\hline $\begin{array}{c}\text { Correlation } \\
\text { coefficient } \\
(\mathrm{r})\end{array}$ & TPC & Carotenoid & DPPH & FRAP & BCBA \\
\hline Carotenoid & 0.905 & & & & \\
DPPH & 0.996 & 0.863 & & & \\
FRAP & 0.93 & $0.998^{*}$ & 0.894 & & \\
BCBA & $0.999^{*}$ & 0.922 & 0.991 & 0.945 & \\
TBA & $0.997^{*}$ & 0.846 & $0.999^{*}$ & 0.878 & 0.986 \\
\hline
\end{tabular}

*significant difference $(\mathrm{p} \leq 0.05)$ for the correlation value between total phenolic, carotenoid and antioxidant activity of chia seed oil.

\section{Conclusion}

The oil yield, total phenolic compounds, total carotenoid contents and antioxidant properties of chia seed oils extracted by hexane (4 hrs) as control and acetone at various extraction times ( $4 \mathrm{hrs}$ and $8 \mathrm{hrs}$ ) were conducted in this study. Simple linear correlation of total antioxidant compounds and antioxidant activity were also observed. Chia seed oil extraction using hexane gave the maximum oil yield. However, increasing of extraction time more than $4 \mathrm{hrs}$ using acetone as a solvent had not significantly $(p>0.05)$ improved the oil recovery of chia seed. Meanwhile, acetone showed an excellent solvent for the extraction of phenolic and carotenoid compounds in chia seed oil. Furthermore, 8 hrs of acetone extraction time enhanced the number of carotenoid contents in chia seed oil. The antioxidant activity of chia seed oil extracted by acetone for $4 \mathrm{hrs}$ exhibits the highest antioxidant capacities (DPPH, BCBA and TBA). However, chia seed oil obtained by hexane as a control showed a weak antioxidant activity in all tests. There was a correlation within the total phenolic compounds, carotenoids and antioxidant activity, which are contributing to the antioxidant potential of chia seed oil. Thus, the results indicate that the utilization of an appropriate solvent in terms of polarity and time of extraction is essential for obtaining chia seed oils with high antioxidant capacity.

\section{Conflict of Interest}

The authors declare no conflict of interest.

\section{Acknowledgements}

This work was supported by the Research University Grant (GUP-2018-018) and Prime Impact Grant (DIP2018-036) from Universiti Kebangsaan Malaysia.
Alothman, M., Bhat, R. and Karim, A.A. (2009). Antioxidant capacity and phenolic content of selected tropical fruits from Malaysia extracted with different solvents. Food Chemistry, 115(3), 785-788. https://doi.org/10.1016/j.foodchem.2008.12.005

Álvarez-Chávez, L.M., Valdivia-López, M.D.L.A., Aburto-Juárez, M.D.L. and Tecante, A. (2008). Chemical characterization of the lipid fraction of Mexican chia seed (Salvia hispanica L.). International Journal of Food Properties, 11(3), 687 -697. https://doi.org/10.1080/10942910701622656

AOAC. (1990). Official Methods of Analysis of the AOAC. $15^{\text {th }}$ ed. Washington DC: Association of Official Analytical Chemists.

Artemis, P. and Simopoulos, M.D. (2002). Omega-3 fatty acids in inflammation and autoimmune diseases. Journal of the American College of Nutrition, 21(6), 495-505. https:// doi.org/10.1080/07315724.2002.10719248

Awolu, O.O. and Manohar, B. (2019). Quantitative and qualitative characterization of mango kernel seed oil extracted using supercritical $\mathrm{CO}_{2}$ and solvent extraction techniques. Heliyon, 5(12), e03068. https://doi.org/10.1016/j.heliyon.2019.e03068

Ayerza, R. (2009). The seed's protein and oil content, fatty acid composition, and growing cycle length of a single genotype of chia (Salvia hispanica L.) as affected by environmental factors. Journal of Oleo Science, 58(7), 347-354. https://doi.org/10.5650/ jos.58.347

Benzie, I.F.F. and Strain, J.J. (1996). The ferric reducing ability of plasma (FRAP) as a measure of "antioxidant power": the FRAP assay. Analytical Biochemistry, 239(1), 70-76. https:// doi.org/10.1006/abio.1996.0292

Borneo, R., Aguirre, A. and León, A.E. (2010). Chia (Salvia hispanica L) gel can be used as egg or oil replacer in cake formulations. Journal of the American Dietetic Association, 110(6), 946-949. https://doi.org/10.1016/j.jada.2010.03.011

Cvetkovikj, I., Stefkov, G., Acevska, J., Stanoeva, J.P., Karapandzova, M., Stefova, M., Dimitrovska, A. and Kulevanova, S. (2013). Polyphenolic characterization and chromatographic methods for fast assessment of culinary Salvia species from South East Europe. Journal of Chromatography A, 1282, 38-45. https://doi.org/10.1016/ j.chroma.2012.12.068

Dąbrowski, G., Konopka, I., Czaplicki, S. and Tańska, M. (2016). Composition and oxidative stability of oil from Salvia hispanica L. seeds in relation to extraction method. European Journal of Lipid

\section{References}


Science and Technology, 119(5), 16002-16009. https://doi.org/10.1002/ejlt.201600209

Dąbrowski, G., Konopka, I. and Czaplicki, S. (2018a). Variation in oil quality and content of low molecular lipophilic compounds in chia seed oils.International Journal of Food Properties, 21(1), 2016-2029. https://doi.org/10.1080/10942912.2018.1501699

Dąbrowski, G., Konopka, I. and Czaplicki, S. (2018b). Supercritical $\mathrm{CO}_{2}$ extraction in chia oils production: impact of process duration and co-solvent addition. Food Science and Biotechnology, 27(3), 677-686. https://doi.org/10.1007/s10068-018-0316-2

Edwards, Q.A., Lunat, I., Neale, L.D.G.-O. and Kulikov, S.M. (2015). Distribution of caffeine between selected water-organic solvent media. International Journal of Chemical Science, 13(3), 1218-1226.

EFSA. (2009). Opinion on the safety of "chia seeds (Salvia Hispanica L.) and ground whole chia seeds" as a food ingredient. EFSA Journal, 996, 1-26.

Ferhat, R., Lekbir, A., Ouadah, H., Kahoul, M.A., Khlalfa, L., Laroui, S. and Alloui-Lombarkia, O. (2017). Effect of extraction solvent on total phenolic content, total flavonoid content, and antioxidant activities of Algerian pomace olive oil. International Food Research Journal, 24(6), 2295-2303.

Fernandes, S.S., Tonato, D., Mazutti, M.A., de Abreu, B.R., Cabrera, D.D.C., D'Oca, C.D.R.M., PrenticeHernández, C. and Salas-Mellado, M.D.L.M. (2019). Yield and quality of chia oil extracted via different methods. Journal of Food Engineering, 262, 200208. https://doi.org/10.1016/j.jfoodeng.2019.06.019

Go, R., Kankara, S.S., Mustafa, M., Ibrahim, H.M. and Nulit, R. (2014). Effect of drying methods, solidsolvent ratio, extraction time and extraction temperature on phenolic antioxidants and antioxidant activity of Guiera senegalensis J.F. Gmel (Combretaceae) leaves water extract. American Journal of Phytomedicine and Clinical Therapeutics, 2(12), 1378-1392.

Haminiuk, C.W.I., Plata-Oviedo, M.S.V., de Mattos, G., Carpes, S.T. and Branco, I.G. (2014). Extraction and quantification of phenolic acids and flavonols from Eugenia pyriformis using different solvents. Journal of Food Science and Technology, 51(10), 28622866. https://doi.org/10.1007/s13197-012-0759-z

Ixtaina, V.Y., Vega, A., Nolasco, S.M., Tomás, M.C., Gimeno, M., Bárzana, E. and Tecante, A. (2010). Supercritical carbon dioxide extraction of oil from Mexican chia seed (Salvia hispanica L.): characterization and process optimization. The Journal of Supercritical Fluids, 55(1), 192-199. https://doi.org/10.1016/j.supflu.2010.06.003
Ixtaina, V.Y., Martínez, M.L., Spotorno, V., Mateo, C.M., Maestri, D.M., Diehl, B.W.K., Nolasco, S.M. and Tomás, M.C. (2011). Characterization of chia seed oils obtained by pressing and solvent extraction. Journal of Food Composition and Analysis, 24(2), 166-174. https://doi.org/10.1016/j.jfca.2010.08.006

Ixtaina, V.Y., Nolasco, S.M. and Tomás, M.C. (2012). Oxidative stability of chia (Salvia hispanica L.) seed oil: effect of antioxidants and storage conditions. Journal of the American Oil Chemists' Society, 89 (6), 1077-1090. https://doi.org/10.1007/s11746-0111990-x

Khajeh, M. (2011). Optimization of process variables for essential oil components from Satureja hortensis by supercritical fluid extraction using Box-Behnken experimental design. Journal of Supercritical Fluids, 55(3), 944-998. https://doi.org/10.1016/ j.supflu.2010.10.017

Kikuzaki H. and Nakatani N. (1993). Antioxidant effects of some ginger constituents. Journal of Food Science, 58(6), 1407-1410. https://doi.org/10.1111/ j.1365-2621.1993.tb06194.x

Kim, J.-H. (2017). Extraction time and temperature affect the extraction efficiencies of coumarin and phenylpropanoids from Cinnamomum cassia bark using a microwave-assisted extraction method. Journal of Chromatography B, 1063, 196-203. https://doi.org/10.1016/j.jchromb.2017.08.008

Litwinienko, G. and Ingold, K.U. (2003). Abnormal solvent effects on hydrogen atom abstraction. 1. The reactions of phenols with 2,2-diphenyl-1picrylhydrazyl (DPPH) in alcohols. The Journal of Organic Chemistry, 68(9), 3433-3438. https:// doi.org/10.1021/jo026917t

Litwinienko, G. and Ingold, K.U. (2004). Abnormal solvent effects on hydrogen atom abstraction. 2 . Resolution of the curcumin antioxidant controversy. The role of sequential proton loss electron transfer. The Journal of Organic Chemistry, 69(18), 58885896. https://doi.org/10.1021/jo049254j

Liu, S.X. and Mamidipally, P.K. (2005). Quality comparison of rice bran oil extracted with Dlimonene and hexane. Cereal Chemistry, 82(2), 209215. https://doi.org/10.1094/CC-82-0209

Mani, S., Jaya, S. and Vadivambal, R. (2007). Optimization of solvent extraction of moringa (Moringa oleifera) seed kernel oil using response surface methodology. Food and Bioproducts Processing, 85(C4), 328-335. https:// doi.org/10.1205/fbp07075

Marineli, R.D.S., Moraes, E.A., Lenquiste, S.A., Godoy, A.T., Eberlin, M.N. and Maróstica Jr., M.R. (2014). 
Chemical characterization and antioxidant potential of Chilean chia seeds and oil (Salvia hispanica L.). LWT - Food Science and Technology, 59(2), 13041310. https://doi.org/10.1016/j.lwt.2014.04.014

Martínez-Cruz, O. and Paredes-López, O. (2014). Phytochemical profile and nutraceutical potential of chia seeds (Salvia hispanica L.) by ultra high performance liquid chromatography. Journal of Chromatography A, 1346, 43-48. https:// doi.org/10.1016/j.chroma.2014.04.007

Maruyama, S.A., Claus, T., Chiavelli, L.U.R., Bertozzi, J., Pilau, E.J., de Souza, N.E., Visentainer, J. V., Gomesa, S.T.M. and Matsushita, M. (2014). Analysis of carotenoids, $\alpha$-tocopherol, sterols and phenolic compounds from white bread enriched with chia (Salvia hispanica L.) seeds and carrot (Daucus carota L.) leaves. Journal of the Brazilian Chemical Society, 25(6), 1108-1115. https:// doi.org/10.5935/0103-5053.20140087

Meneses, N.G.T., Martins, S., Teixeira, J.A. and Mussatto, S.I. (2013). Influence of extraction solvents on the recovery of antioxidant phenolic compounds from brewer's spent grains. Separation and Purification Technology, 108, 152-158. https:// doi.org/10.1016/j.seppur.2013.02.015

Mínguez Mosquera, M.I., Rejano, L., Gandul, B., Sánchez, A. H. and Garrido, J. (1991). Colorpigment correlation in virgin olive oil. Journal of the American Oil Chemists' Society, 68(5), 332-336. https://doi.org/10.1007/BF02657688

Moon, J.K. and Shibamoto, T. (2009). Antioxidant assays for plant and food components. Journal of Agricultural and Food Chemistry, 57(5), 1655-1666. https://doi.org/10.1021/jf803537k

Moradi, N., Rahimi, M., Moeini, A. and Parsamoghadam, M.A. (2018). Impact of ultrasound on oil yield and content of functional food ingredients at the oil extraction from sunflower. Separation Science and Technology, 53(2), 261-276. https://doi.org/10.1080/01496395.2017.1384016

Mridula, D., Barnwal, P. and Singh, K.K. (2015). Screw pressing performance of whole and dehulled flaxseed and some physic-chemical characteristics of flaxseed oil. Journal of Food Science and Technology Mysore, 52(3), 1498-1506. https:// doi.org/10.1007/s13197-013-1132-6

Müller, L., Fröhlich, K. and Böhm, V. (2011). Comparative antioxidant activities of carotenoids measured by ferric reducing antioxidant power (FRAP), ABTS bleaching assay ( $\alpha$ TEAC), DPPH assay and peroxyl radical scavenging assay. Food Chemistry, 129(1), 139-148. https://doi.org/10.1016/ j.foodchem.2011.04.045
Muñoz, L.A., Cobos, A., Diaz, O. and Aguilera, J.M. (2013). Chia seed (Salvia hispanica L.): An ancient grain and a new functional food. Food Reviews International, 29(4), 394-408. https:// doi.org/10.1080/87559129.2013.818014

Naczk, M. and Shahidi, F. (2006). Phenolics in cereals, fruits and vegetables: occurrence, extraction and analysis. Journal of Pharmaceutical and Biomedical Analysis, 41(5), 1523-1542. https://doi.org/10.1016/ j.jpba.2006.04.002

Norshazila, S., Koy, C.N., Rashidi, O., Ho, L.H., Azrina, I., Nurul Zaizuliana, R.A. and Zarinah, Z. (2017). The effect of time, temperature and solid to solvent ratio on pumpkin carotenoids extracted using food grade solvents. Sains Malaysiana, 46(2), 231-237. https://doi.org/10.17576/jsm-2017-4602-07

Noshe, A.S. and Al-bayyar, A.H. (2017). Effect of extraction method of chia seeds oil on its content of fatty acids and antioxidants. International Research Journal of Engineering and Technology, 4(10), 545551.

Okeleye, A.A. and Betiku, E. (2019). Kariya (Hildegardia barteri) seed oil extraction: comparative evaluation of solvents, modelling, and optimization techniques. Chemical Engineering Communications, 206(9), 1181-1198. https:// doi.org/10.1080/00986445.2018.1550397

Oliveira-Alves, S.C., Vendramini-Costa, D.B., Betim Cazarin, C.B., Maróstica Júnior, M.R., Borges Ferreira, J.P., Silva, A.B., Prado, M.A. and Bronze, M.R. (2017). Characterization of phenolic compounds in chia (Salvia hispanica L.) seeds, fiber flour and oil. Food Chemistry, 232, 295-305. https:// doi.org/10.1016/j.foodchem.2017.04.002

Pichai, E. and Krit, A. (2015). Optimization of solid-tosolvent ratio and time for oil extraction process from spent coffee grounds using response surface methodology. ARPN Journal of Engineering and Applied Sciences, 10, 7049-7052.

Reyes-Caudillo, E., Tecante, A. and Valdivia-López, M.A. (2008). Dietary fibre content and antioxidant activity of phenolic compounds present in Mexican chia (Salvia hispanica L.) seeds. Food Chemistry 107(2), 656-663. https://doi.org/10.1016/ j.foodchem.2007.08.062

Rosas-Mendoza, M.E., Coria-Hernández, J., MeléndezPérez, R. and Arjona-Román, J.L. (2017). Characteristics of chia (Salvia hispanica L.) seed oil extracted by ultrasound assistance. Journal of Mexican Chemical Society, 61(4), 326-335. https:// doi.org/10.29356/jmcs.v61i4.463

Routray, W. and Orsat, V. (2012). Microwave-assisted 
extraction of flavonoids: a review. Food and Bioprocess Technology, 5(2), 409-424. https:// doi.org/10.1007/s11947-011-0573-z

Ruttarattanamongkol, K. and Petrasch, A. (2016). Oxidative susceptibility and thermal properties of Moringa oleifera seed oil obtained by pilot-scale subcritical and supercritical carbon dioxide extraction. Journal of Food Process Engineering, 39 (3), 226-236. https://doi.org/10.1111/jfpe.12213

Sahreen, S., Khan, M.R. and Khan, R.A. (2011). Phenolic compounds and antioxidant activities of Rumex hastatus D. Don. leaves. Journal of Medicinal Plants Research, 5(13), 2755-2765.

Sang, S., Lapsley, K., Jeong, W.S., Lachance, P.A., Ho, C.T. and Rosen, R.T. (2002). Antioxidative phenolic compounds isolated from almond skins (Prunus amygdalus Batsch). Journal of Agricultural and Food Chemistry, 50(8), 2459-2463. https:// doi.org/10.1021/jf011533+

Saphier, O., Silberstein, T., Kamer, H., Ben-abu, Y. and Tavor, D. (2017). Chia seeds are richer in polyphenols compared to flax seeds. Integrative Food, Nutrition and Metabolism, 4(3), 1-4. https:// doi.org/10.15761/IFNM.1000182

Sargi, S.C., Silva, B.C., Santos, H.M.C., Montanher, P.F., Boeing, J.S., Santos Júnior, O.O., Souza, N.E. and Visentainer, J.V. (2013). Antioxidant capacity and chemical composition in seeds rich in omega-3: chia, flax, and perila. Food Science and Technology, 33(3), 541-548. https://doi.org/10.1590/S010120612013005000057

Scapin, G., Abaide, E.R., Nunes, L.F., Mazutti, M.A., Vendruscolo, R.G., Wagner, R. and da Rosa, C.S. (2017). Effect of pressure and temperature on the quality of chia oil extracted using pressurized fluids. The Journal of Supercritical Fluids, 127, 90-96. https://doi.org/10.1016/j.supflu.2017.03.030

Shen, Y., Zheng, L., Jin, J., Li, X., Fu, J., Wang, M., Guan, Y. and Song, X. (2018). Phytochemical and biological characteristics of Mexican chia seed oil. Molecules, 23(12), 3219. https://doi.org/10.3390/ molecules 23123219

Shon, M.Y., Kim, T.H. and Sung, N.J. (2003). Antioxidants and free radical scavenging activity of Phellinus baumii (Phellinus of Hymenochaetaceae) extracts. Food Chemistry, 82(4), 593-597. https:// doi.org/10.1016/S0308-8146(03)00015-3

Siddhuraju, P., Mohan, P.S. and Becker, K. (2002). Studies on the antioxidant activity of Indian Laburnum (Cassia fistula L.): a preliminary assessment of crude extracts from stem bark, leaves, flowers and fruit pulp. Food Chemistry, 79(1), 61-
67. https://doi.org/10.1016/S0308-8146(02)00179-6

SIAR (SIDS Initial Assessment Report). (1999). 9th SIAM, Acetone, Paris, France. Retrieved on June 2930, 1999 from INCHEM Website: www.inchem.org/ documents/sids/sids/67641.pdf

Silva, C., Garcia, V.A.S. and Zanette, C.M. (2016). Chia (Salvia hispanica L.) oil extraction using different organic solvents: oil yield, fatty acids profile and technological analysis of defatted meal. International Food Research Journal, 23(3), 9981004.

Singleton, V.L., Orthofer, R. and Lamuela-Raventós, R.M. (1999). Analysis of total phenols and other oxidation substrates and antioxidants by means of folin-ciocalteu reagent. Methods in Enzymology, 299, 152-178. https://doi.org/10.1016/S0076-6879 (99)99017-1

Sri Widyawati, P., Budianta, T.D.W., Kusuma, F.A. and Wijaya, E.L. (2014). Difference of solvent polarity to phytochemical content and antioxidant activity of Pluchea indicia less leaves extracts. International Journal of Pharmacognosy and Phytochemical Research, 6(4), 850-855.

Tan, M.C., Tan, C.P. and Ho, C.W. (2013). Effects of extraction solvent system, time and temperature on total phenolic content of henna (Lawsonia inermis) stems. International Food Research Journal, 20(6), 3117-3123.

Tepe, B., Sokmen, M., Akpulat, H.A. and Sokmen, A. (2006). Screening of the antioxidant potentials of six Salvia species from Turkey. Food Chemistry, 95(2), 200-204.

j.foodchem.2004.12.031

Turkmen, N., Poyrazoglu, E.S., Sari, F. and Velioglu, Y.S. (2006). Effects of cooking methods on chlorophylls, pheophytins and colour of selected green vegetables. International Journal of Food Science and Technology, 41(3), 281-288. https:// doi.org/10.1111/j.1365-2621.2005.01061.x

Ullah, R., Nadeem, M., Ayaz, M., Imran, M. and Tayyab, M. (2016). Fractionation of chia oil for enrichment of omega 3 and 6 fatty acids and oxidative stability of fractions. Food Science and Biotechnology, 25(1), 41-47. https://doi.org/10.1007/ s10068-016-0006-x

Valgimigli, L., Amorati, R., Petrucci, S., Peduli, G.F., Hu, D., Hanthorn, J.J. and Pratt, D.A. (2009). Unexpected acid catalysis in reaction of peroxyl radicals with phenols. Angewandte Chemie International Edition, 48(44), 8348-8351. https:// doi.org/10.1002/anie.200903360

Yunfeng, Z., Lin, L., Lan, S., Lidong, Z. and Yang, X. 
(2018). In comparison with vitamin $\mathrm{C}$ and butylated hydroxytoluene, the antioxidant capacity of aqueous extracts from buds and flowers of Lonicera japonica Thunb. Journal of Traditional Chinese Medicine, 38 (3), 373-379. https://doi.org/10.1016/S0254-6272 (18)30627-7

Zaki, E.F. (2018). Impact of adding chia seeds (Salvia hispanica L.) on the quality properties of camel burger "Camburger" during cold storage. International Journal of Current Microbiology and Applied Sciences, 7(3), 1356-1363. https:// doi.org/10.20546/ijcmas.2018.703.162

Zhuang, X., Zhang, Z., Wang, Y. and Li, Y. (2018). The effect of alternative solvents to n-hexane on the green extraction of Litsea cubeba kernel oils as new oil sources. Industrial Crops and Products, 126, 340 -346. https://doi.org/10.1016/j.indcrop.2018.10.004 